\title{
Percutaneous two unilateral iliosacral S1 screw fixation for pelvic ring injuries: a retrospective review of $\mathbf{3 8}$ patients
}

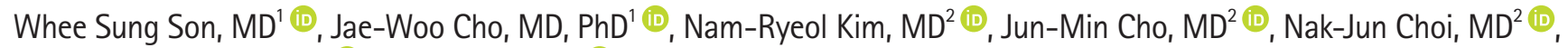 \\ Jong-Keon Oh, MD, PhD ${ }^{1}$, HanJu Kim, MD' (iD \\ 'Department of Orthopedic Surgery, Korea University Guro Hospital, Seoul, Korea \\ ${ }^{2}$ Department of General Surgery, Korea University Guro Hospital, Seoul, Korea
}

Received: September 11, 2021

Revised: October 8, 2021

Accepted: October 19, 2021

Correspondence to

HanJu Kim, MD

Department of Orthopedic Surgery,

Korea University Guro Hospital, 148

Gurodong-ro, Guro-gu, Seoul 08308,

Korea

Tel: +82-2-2626-1869

E-mail: hjkimortho@gmail.com
Purpose: Percutaneous iliosacral (IS) screw fixation for pelvic ring injuries is a minimally invasive technique that reduces the amount of blood loss and shortens the procedure time. Moreover, two unilateral IS S1 screws exhibit superior stability to a single IS screw and are also safer for neurological injuries than an S2 screw. Therefore, this study aimed to evaluate fixation using percutaneous two unilateral IS S1 screws for pelvic ring injuries and its subsequent clinical outcomes.

Methods: We retrospectively reviewed 38 patients who underwent percutaneous two unilateral IS S1 screw fixation for pelvic ring injuries. The procedure time, blood loss, achievement of bone union, radiological outcomes (Matta and Tornetta grade), and postoperative complications were evaluated. Results: The mean procedure time, hemoglobin loss, bone union rate, and time to union were 40.1 minutes (range, 18-102 minutes), 0.6 g/dL (range, 0.3-1.0 g/dL), 100\%, and 153.2 days (range, 61-327 days), respectively. The Matta and Tornetta grades were excellent, good, and fair in 24 (63.1\%), 11 (28.9\%), and three patients (7.9\%), respectively, and the postoperative complications were S1 screw loosening, widening of the symphysis pubis ( 2.3 and $2.5 \mathrm{~mm}$ ), lumbosacral plexopathy, and S1 radiculopathy in one (2.6\%), two (5.3\%), one (2.6\%), and one patient (2.6\%), respectively. However, all neurological complications recovered spontaneously.

Conclusions: Percutaneous two unilateral IS S1 screw fixation was useful for treating pelvic ring injuries. In particular, it involved a short procedure time with little blood loss and also led to $100 \%$ bone union and good radiological outcomes.

Keywords: Pelvic bones; Fracture fixation; Minimally invasive surgical procedures; Bone screws

\section{INTRODUCTION}

Percutaneous iliosacral (IS) screw fixation for pelvic ring injuries is a minimally invasive technique that more effectively reduces blood loss and operative time than the open reduction technique [1-3]. Thus, it has several advantages, particularly in patients

(C) 2022 The Korean Society of Traumatology

This is an Open Access article distributed under the terms of the Creative Commons Attribution Non-Commercial License (http://creativecommons.org/licenses/by-nc/4.0/) which permits unrestricted non-commercial use, distribution, and reproduction in any medium, provided the original work is properly cited. 
with unstable hemodynamic conditions. However, the use of one IS screw is inferior with respect to rotational stability and load cycles $[4,5]$. Therefore, the fixation of two unilateral IS S1 screws or the addition of an IS S2 screw is recommended in completely unstable pelvic ring injuries [4]. Among these two procedures, the fixation of two unilateral IS S1 screws can be a reasonable option for unstable pelvic ring injuries, considering that IS screw positioning in $\mathrm{S} 1$ is safer in iatrogenic neurological injuries than IS screw positioning in S2 [6].

However, limited data have been reported on the clinical outcomes of two unilateral IS S1 screw fixation. Only one study has evaluated the functional and radiological outcomes of two unilateral IS S1 screw fixation and compared them with the outcomes of single IS S1 screw fixation [7]. Moreover, no other studies have evaluated the clinical outcomes of two unilateral IS S1 screw fixation. Therefore, this study aimed to retrospectively review patients who underwent percutaneous two unilateral IS S1 screw fixation and evaluate their clinical outcomes.

\section{METHODS}

This study was a retrospective review of a prospectively collected cohort at a level 1 trauma center, Korea University Guro Hospital and approved by the Institutional Review Board of the Korea University Guro Hospital (No. 2021GR0439).

\section{Patients}

In total, 221 patients who underwent surgery for unstable pelvic ring injuries from May 2012 to May 2021 were reviewed. The inclusion criteria for these patients were as follows: (1) fixation of two ipsilateral IS S1 screws (7.3 or $7.0 \mathrm{~mm}$ ); (2) fixation procedure performed percutaneously under two-dimensional fluoroscopic guidance; (3) at least a 1-year postoperative follow-up; and (4) available medical charts and radiographs to review exact data. Of the 221 patients, 38 patients were included in the analysis. Table 1 shows the included patients' demographic data, and Table 2 shows the fixation constructs of the included patients.

\section{Surgical technique}

Before surgery, we measured the inlet angle, which is tangent to the anterior cortex of $S 1$, and the outlet angle, which is perpendicular to the midline of the trapezoidal S1 body, using a midline sagittal computed tomography (CT) image (Fig. 1A). Based on the measured angles and fluoroscopic findings, we accurately determined the angle of the inlet and outlet views. The inlet view visualized the anterior cortex of the S1 body and spinal canal, whereas the outlet view visualized the sacral foramen (Fig. 2A). Lines perpendicular to the determined inlet and outlet angles were drawn on the patient along with the line of iliac cortical density (ICD), which could be confirmed in the true lateral view (Fig. 1B). Surgery was then performed on a radiolucent operating table, and the patient was prepared in the supine position. The entry of the first guide pin was made anterior in S1 and inferior to ICD. The height of the entry and coronal direction of the guide pin were determined via the outlet view, and the anteri-

Table 1. Demographic characteristics of the included patients

\begin{tabular}{|c|c|}
\hline Characteristic & Value $(n=38)$ \\
\hline Age (yr) & $51(14-78)$ \\
\hline Sex (male:female) & $19(50): 19(50)$ \\
\hline \multicolumn{2}{|l|}{ Mechanism of injury } \\
\hline Fall down & $12(31.6)$ \\
\hline Crushing injury & $5(13.2)$ \\
\hline Pedestrian injury & $13(34.2)$ \\
\hline Motor vehicle injury & $5(13.2)$ \\
\hline Bicycle injury & $1(2.6)$ \\
\hline Slip down & $2(5.3)$ \\
\hline Injury Severity Score & $19.57(4-50)$ \\
\hline \multicolumn{2}{|l|}{ Young-Burgess classification } \\
\hline LC type I & $6(15.8)$ \\
\hline LC type II & $19(50.0)$ \\
\hline LC type III & $4(10.5)$ \\
\hline APC type II & $3(7.9)$ \\
\hline APC type III & $4(10.5)$ \\
\hline VS type & $1(2.6)$ \\
\hline \multicolumn{2}{|l|}{ Tile classification } \\
\hline $\mathrm{B} 1$ & $2(5.3)$ \\
\hline B2 & $13(34.2)$ \\
\hline B3 & $1(2.6)$ \\
\hline $\mathrm{C} 1$ & $8(21.1)$ \\
\hline $\mathrm{C} 2$ & $13(34.2)$ \\
\hline $\mathrm{C} 3$ & $1(2.6)$ \\
\hline \multicolumn{2}{|l|}{ Location of posterior pelvic injury } \\
\hline Sacroiliac joint (involving crescent fracture) & $18(47.3)$ \\
\hline Sacral zone I & $6(15.8)$ \\
\hline Sacral zone II & $13(34.2)$ \\
\hline Sacral zone III & $1(2.6)$ \\
\hline \multicolumn{2}{|l|}{ Type of anterior pelvic ring injury } \\
\hline Unilateral rami fracture & $16(42.1)$ \\
\hline Bilateral rami fracture & $14(36.8)$ \\
\hline Pubic symphysis diastasis & $7(18.4)$ \\
\hline Vertical displacement of the pubic symphysis & $1(2.6)$ \\
\hline
\end{tabular}

Values are presented as mean (range) or number (\%).

LC, lateral compression; APC, anterior-posterior compression; VS, vertical shear. 
Table 2. Fixation constructs of the included patients

\begin{tabular}{lc}
\hline Fixation construct & Value $(\mathrm{n}=38)$ \\
\hline Type of two S1 screws & \\
$\quad$ Two partially threaded screws & $4(10.5)$ \\
$\quad \begin{array}{l}\text { One partially threaded screw and one fully thread- } \\
\text { ed screw }\end{array}$ & $18(47.4)$ \\
$\quad$ Two fully threaded screws & $16(42.1)$ \\
Combined posterior fixation & \\
$\quad$ None & $20(52.6)$ \\
Iliosacral S2 screw & $10(26.3)$ \\
Transiliac-transsacral S2 screw & $6(15.8)$ \\
Contralateral iliosacral S1 screw & $2(5.3)$ \\
Combined anterior fixation & $12(31.6)$ \\
None & $8(21.0)$ \\
Retrograde pubic ramus screw & $18(47.4)$ \\
Plate &
\end{tabular}

Values are presented as number (\%).

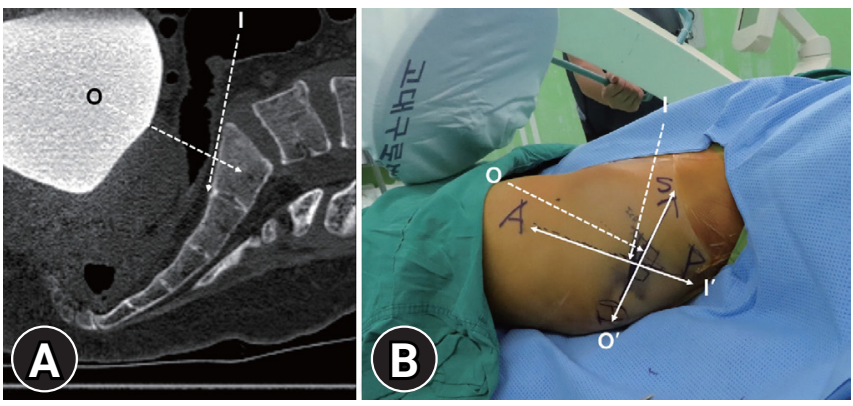

Fig. 1. Computed tomography image and clinical photograph of the preoperative preparation. (A) The measured inlet angle is tangent to the anterior cortex of S1 (dotted line I) and the outlet angle is perpendicular to the midline of the S1 body (dotted line O). (B) The drawn lines are perpendicular to the determined inlet (line I') and outlet angles (line O'); and the drawn dotted lines are determined inlet angle (dotted line I) and outlet angle (dotted line O). The patient provided written informed consent for publication of the research details and clinical images.

or-posterior position and direction were determined through the inlet view (Fig. 2B, C). The drawn perpendicular line of the determined inlet and outlet angles helped modify the position of the guide pin entry and direction of the guide pin. For example, if the guide pin position or direction needed modification in the outlet view, moving the pin along the line drawn perpendicular to the outlet angle could modify the position or direction of the pin effectively in the outlet view. After making the accurate position of entry and direction, we advanced the guide pin. The guide pin was advanced cranial to the $\mathrm{S} 1$ foramen in the outlet view and near the anterior cortex, but within it, in the inlet view (Fig. 2D, E). After passing the S1 foramen, the true lateral view was used to confirm that the ICD had not been penetrated, and the guide pin was then advanced to the S1 body (Fig. 2F). Finally, reaming was performed, and a cannulated screw with a washer was inserted via the guide pin. When tightening the screws, the obturator inlet view was used to confirm the narrowing of the sacroiliac joint gap, thereby confirming the precise state of the screw head and washer to prevent excessive intrusion (Fig. 2GI). The second unilateral IS screw was fixed whenever possible; however, if the safe corridor was not sufficiently wide and pelvic dysmorphism was observed, the second screw was not used. The guide pin of the second screw was inserted; the guide pin of the first screw was not removed because it helped to guide the direction of the second guide pin (Fig. 3A). The second guide pin was positioned cranial to the first screw in the outlet view and positioned in a manner that did not penetrate the anterior cortex or the spinal canal in the inlet view and ICD in the lateral view (Fig. 3A-C). As a result, the second guide pin usually overlapped with or was slightly posterior to the first screw. The interval between the first screw and the second guide pin was at least half of the screw diameter to prevent collision between the screws. After confirming the adequate position of the second guide pin, the second screw was inserted (Fig. 3D-F). The type of screws was selected based on the need for compression. If compression was not required or overcompression needed to be avoided, a fully threaded screw was fixed. If compression was required, a partially threaded screw was fixed. Moreover, if additional compression was required after the first partially threaded screw fixation, the second screw was also selected for the partially threaded screw. A washer was routinely applied.

\section{Postoperative management}

All patients were instructed to perform a hip joint range of motion exercise and quadriceps strengthening exercises immediately after surgery. Furthermore, "toe-touch" weight-bearing to partial weight-bearing immediately after surgery was initially advised to patients with vertically stable injuries. However, patients with vertically unstable injuries started partial weight-bearing 4 to 6 weeks postoperatively. Thereafter, we progressively increased the amount of weight-bearing according to patients' tolerance. The patients were followed up at 2 weeks, 6 weeks, 3 months, 6 months, and 1 year postoperatively.

\section{Outcome measurements}

The procedure time was evaluated using fluoroscopic data. Because all procedures were performed under fluoroscopic guidance, we could determine the exact start and end times of the 

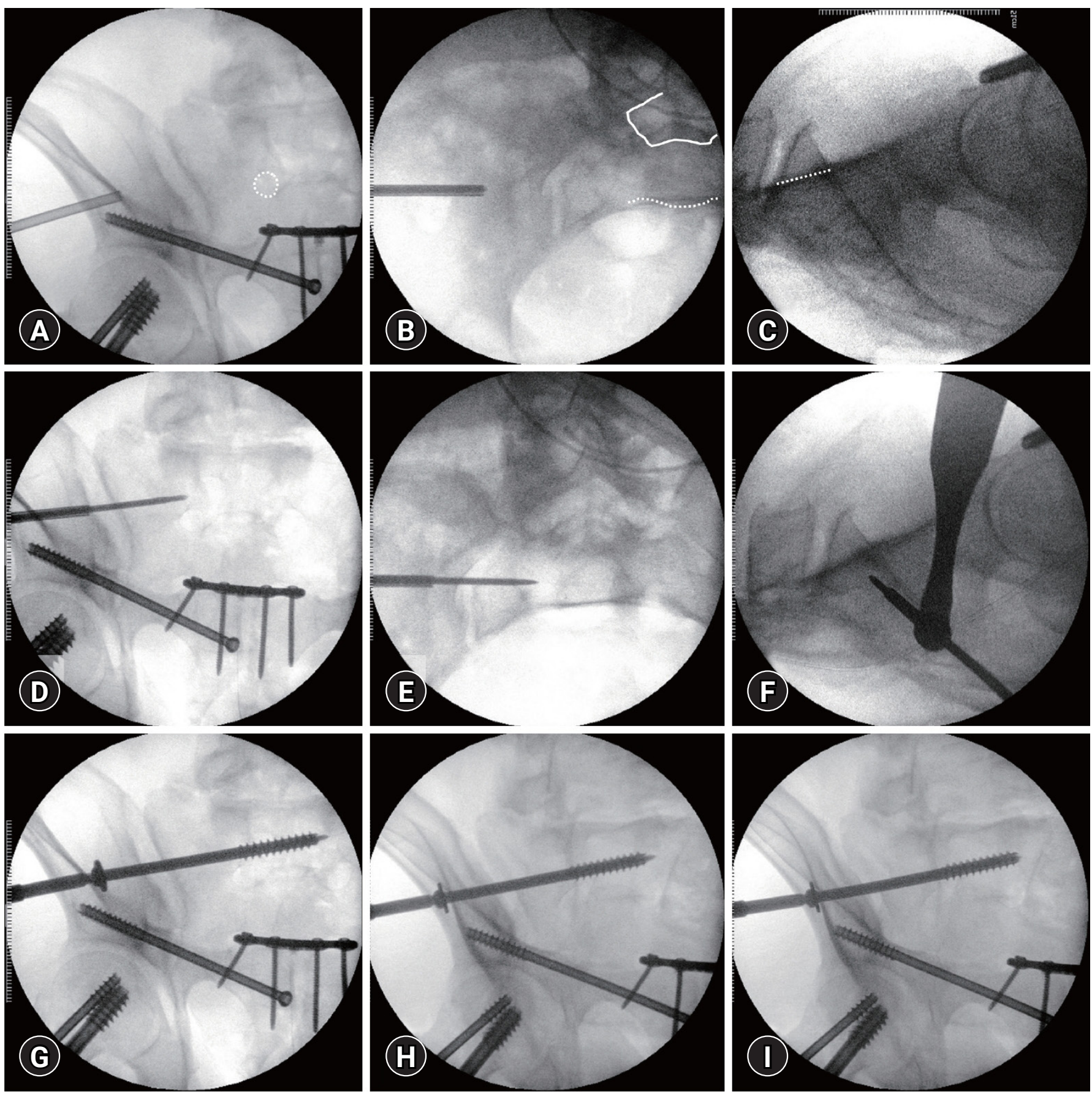

Fig. 2. Fluoroscopic images of the first iliosacral screw procedure. (A) Image of the outlet view visualizing the $\mathrm{S} 1$ foramen and determining the height of entry and coronal direction of the guide pin. The dotted line indicates the right S1 foramen. (B) Inlet view visualizing the anterior cortex of the S1 body and spinal canal and determining the anterior-posterior position and direction of the guide pin. The dotted lines indicate the anterior cortex of the S1 body, and the lines indicate the spinal canal. (C) Lateral view showing the iliac cortical density (ICD) line. The dotted lines indicate the ICD. (D) Outlet view showing that the guide wire should be cranial to the S1 foramen. (E) Inlet view showing that the guide wire should not penetrate the anterior cortex or the spinal canal. (F) Lateral view demonstrating that the guide wire is not penetrating the ICD after passing the S1 foramen. (G, H) Outlet and oblique inlet views show the sacroiliac joint gap and precise state of the screw and washer before tightening of the screw. (I) Oblique inlet view demonstrates both a compressed sacroiliac joint and an unintruded screw head and washer into the ilium. The patient provided written informed consent for publication of the research details and clinical images. 

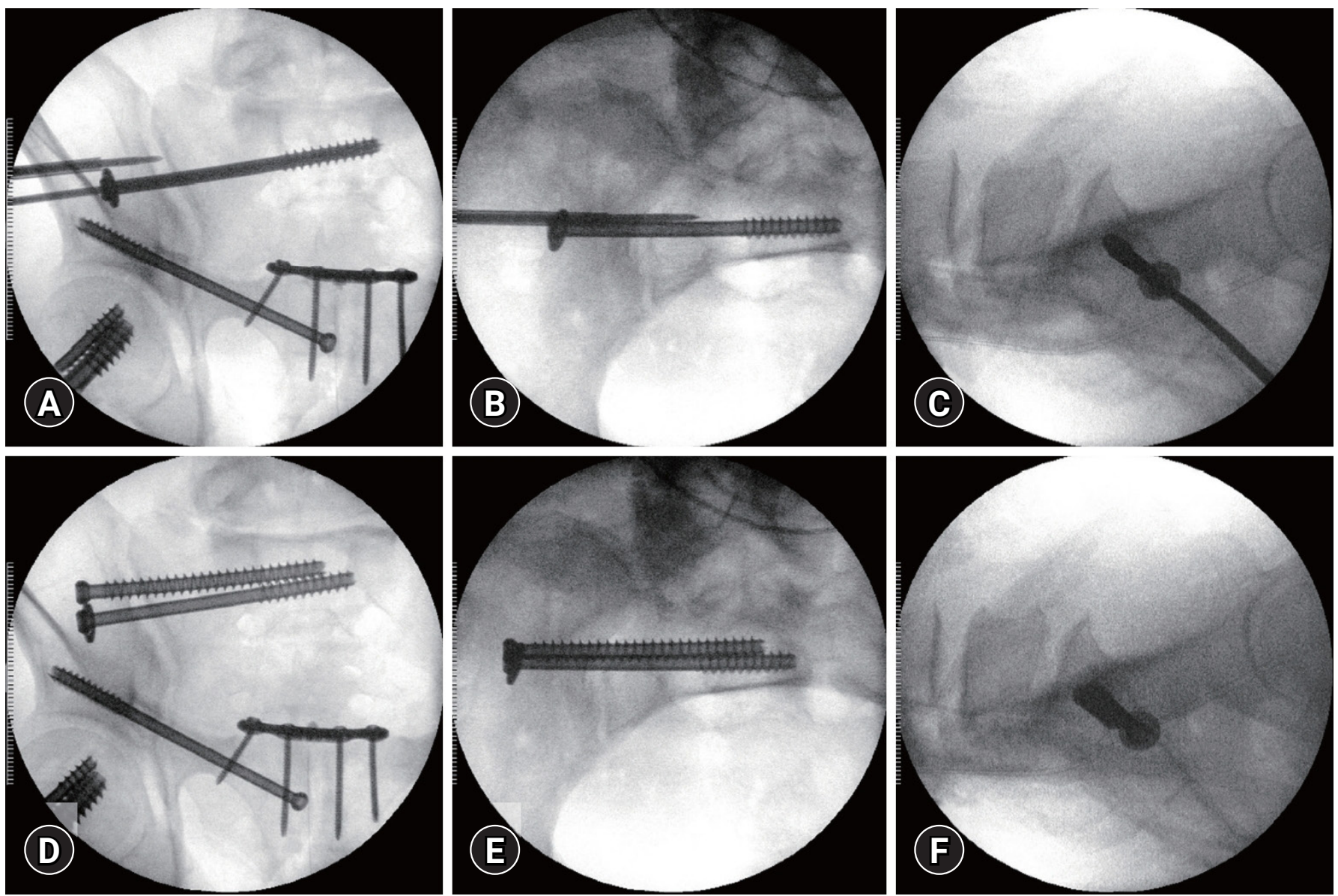

Fig. 3. Fluoroscopic images of the second iliosacral screw procedure. (A) Outlet view showing that both the first and second screws are cranial to the $\mathrm{S} 1$ foramen and that the first guide pin was not removed to help guide the first guide pin. (B) Inlet view showing that the second guide pin is not penetrating the anterior cortex or the spinal canal. (D) Lateral view showing that the second guide pin is not penetrating the iliac cortical density line. (E, F) Final position of the second iliosacral screw. The patient provided written informed consent for publication of the research details and clinical images.

procedure using fluoroscopic data. If surgery involved only percutaneous two ipsilateral S1 screw fixation with intraoperative transfusion, blood loss was evaluated using hemoglobin $(\mathrm{Hb})$ loss between the preoperative and postoperative periods. Intraoperative complications (e.g., guide wire breakage) were also evaluated. Bone union was defined as the absence of a fracture line. In addition, the time to union was evaluated. Moreover, we measured radiological outcomes using the method of Matta and Tornetta [8]; reductions were graded as excellent $(<4 \mathrm{~mm})$, good (5-10 mm), fair (11-20 mm), and poor ( $>20 \mathrm{~mm}$ ) using maximal displacement measured on the three standard radiographic views of the pelvis. The bone union and radiographic outcomes were determined by a consensus of two orthopedic trauma fellowship-trained independent observers who were blinded to clinical information. Finally, several postoperative complications, including reduction loss, implant loosening or failure, neurologi- cal complication, and infection, were evaluated.

\section{RESULTS}

The mean procedure time was 40.1 minutes (range, 18-102 minutes). Blood loss was evaluated in five patients, and the mean $\mathrm{Hb}$ loss was $0.6 \mathrm{~g} / \mathrm{dL}$ (range, $0.3-1.0 \mathrm{~g} / \mathrm{dL}$ ). There were no intraoperative complications. Bone union was achieved in all 38 patients; hence, the bone union rate was $100 \%$. The mean time to union was 153.2 days (range, 61-327 days). The Matta and Tornetta grades were as follows: excellent in 24 (63.2\%), good in 11 (28.9\%), fair in three (7.9\%), and poor in zero patients. S1 screw loosening was observed in one patient, combined S2 screw loosening in two patients, widening of the symphysis pubis (2.3 and $2.5 \mathrm{~mm}$ ) in two patients, and infection of the anterior pelvic implant in one patient. Moreover, lumbosacral plexopathy was ob- 
Table 3. Outcomes of ipsilateral two S1 iliosacral screws

\begin{tabular}{lc}
\hline Outcome measurement & Value \\
\hline Procedure time (min) & $40.1(18-102)$ \\
Hemoglobin loss (g/dL) (n=5) & $0.6(0.3-1.0)$ \\
Bone union rate & $38 / 38(100.0)$ \\
Time to bone union (day) & $153.2(61-327)$ \\
Matta and Tornetta's grade & \\
$\quad$ Excellent & $24(63.2)$ \\
Good & $11(28.9)$ \\
Fair & $3(7.9)$ \\
Poor & 0 \\
Intraoperative complication & 0 \\
Postoperative complication & \\
S1 screw loosening & $1(2.6)$ \\
Combined S2 screw loosening & $2(5.3)$ \\
Widened symphysis pubis ${ }^{\text {a) }}$ & $2(5.3)$ \\
Infection of the anterior pelvic implant & $1(2.6)$ \\
Lumbosacral plexopathy ${ }^{b}$ & $1(2.6)$ \\
S1 radiculopathy & $1(2.6)$ \\
\hline
\end{tabular}

Values are presented as mean (range) or number (\%).

a) The widened distances of the symphysis pubis were $2.3 \mathrm{~mm}$ and 2.5

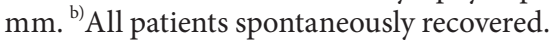

served in one patient and S1 radiculopathy in one patient; however, all cases recovered spontaneously (Table 3, Fig. 4).

\section{DISCUSSION}

The present study demonstrated that percutaneous two unilateral IS S1 screw fixation for pelvic ring injuries required a mean procedure time of 40.1 minutes and led to a mean $\mathrm{Hb}$ loss of $0.6 \mathrm{mg} /$ $\mathrm{dL}$ during the procedure, a union rate of $100 \%$, and an excellent to good radiological grade of $92.1 \%$.

The biomechanical analysis of IS screws has been performed in several studies. Yinger et al. [9] compared nine different posterior pelvic ring fixation methods on hard plastic pelvic models, and the results revealed that two unilateral IS S1 screws were significantly stiffer in horizontal plane gapping and coronal plane rotation than single IS S1 screws, two anterior sacroiliac plates, one posterior pelvic tension band plate, one posterior pelvic tension band plate combined with one IS S1 screw, two transiliac bars, two transiliac bars combined with an IS screw, and one transiliac bar with one IS S1 screw. van Zwienen et al. [4] compared two unilateral IS S1 screws and a single IS S1 screw in a type $\mathrm{C}$ pelvic ring injury cadaveric model. The results showed that the two unilateral IS S1 screws were significantly stiffer in terms of rotation and load to failure than a single IS S1 screw. Moreover, Salari et al. [10] compared two unilateral IS S1 screws and one IS S1 screw with a transsacral S1 screw in a type C pelvic ring injury cadaveric model. They concluded that although a transsacral screw may appear to be more stable, the use of two long unilateral IS SI screws yielded adequate stability in a single-limb stance-testing model compared with transsacral S1 screws. These studies demonstrated the usefulness of two unilateral IS S1 screws with respect to mechanical stability.

Only one study, however, has evaluated the clinical outcomes of two unilateral IS S1 screws to date. The authors compared radiological outcomes via the Matta and Tornetta grade and functional outcomes using the Majeed scoring system. Although the outcomes of both groups were comparable to those of other studies with respect to pelvic ring injuries, the outcomes showed no statistically significant differences between the two groups [7]. However, they did not report patient-related variables (e.g., age, fracture type, or combined injury) of each group and their differences. Therefore, selection bias could not be excluded with regard to the results of the previous study [7]. Suda et al. [5] recently evaluated the safety of two unilateral IS S1 screws in a three-dimensional dataset of 1,000 hemi-pelvises of 500 patients with trauma. They concluded that $99 \%$ of male and $96 \%$ of female hemi-pelvises had adequate room to place two 7.3-mm screws at a 5-mm distance into the $\mathrm{S} 1$ vertebra. In addition, they stated that two unilateral IS S1 screws increased the mechanical stability and posed a lower risk for neurological injuries than the positioning of additional $\mathrm{S} 2$ screws.

In the present study, the mean procedure time of percutaneous two unilateral IS S1 screw fixation was 40.1 minutes, which is comparable to the procedure time in previous studies that used a single IS screw. Routt et al. [11] reported that one percutaneous IS screw required a mean procedure time of 26 minutes, implying that 2-screw fixation would require a mean time of $52 \mathrm{~min}$ utes. Gras et al. [12] reported a mean time of 62 minutes for one percutaneous screw fixation for pelvic ring injury. Although positioning the second IS S1 screw to avoid the first IS S1 screw can be intuitively difficult and may need a longer time, it did not require more time in the present study. Thus, two unilateral IS S1 screws still have the advantage of a short procedure time for performing the percutaneous IS screw technique. We evaluated blood loss by measuring the decrease in $\mathrm{Hb}$ levels between the preoperative and postoperative periods, although most other studies utilized intraoperative blood loss volume. Because intraoperative blood loss volume cannot be evaluated objectively and is often estimated, we used $\mathrm{Hb}$ loss instead. The mean $\mathrm{Hb}$ loss of $0.6 \mathrm{~g} / \mathrm{dL}$ was small, which is beneficial for hemodynamically unstable patients. Moreover, all patients showed bone union, and bone union required a mean duration of 153.2 days. These re- 

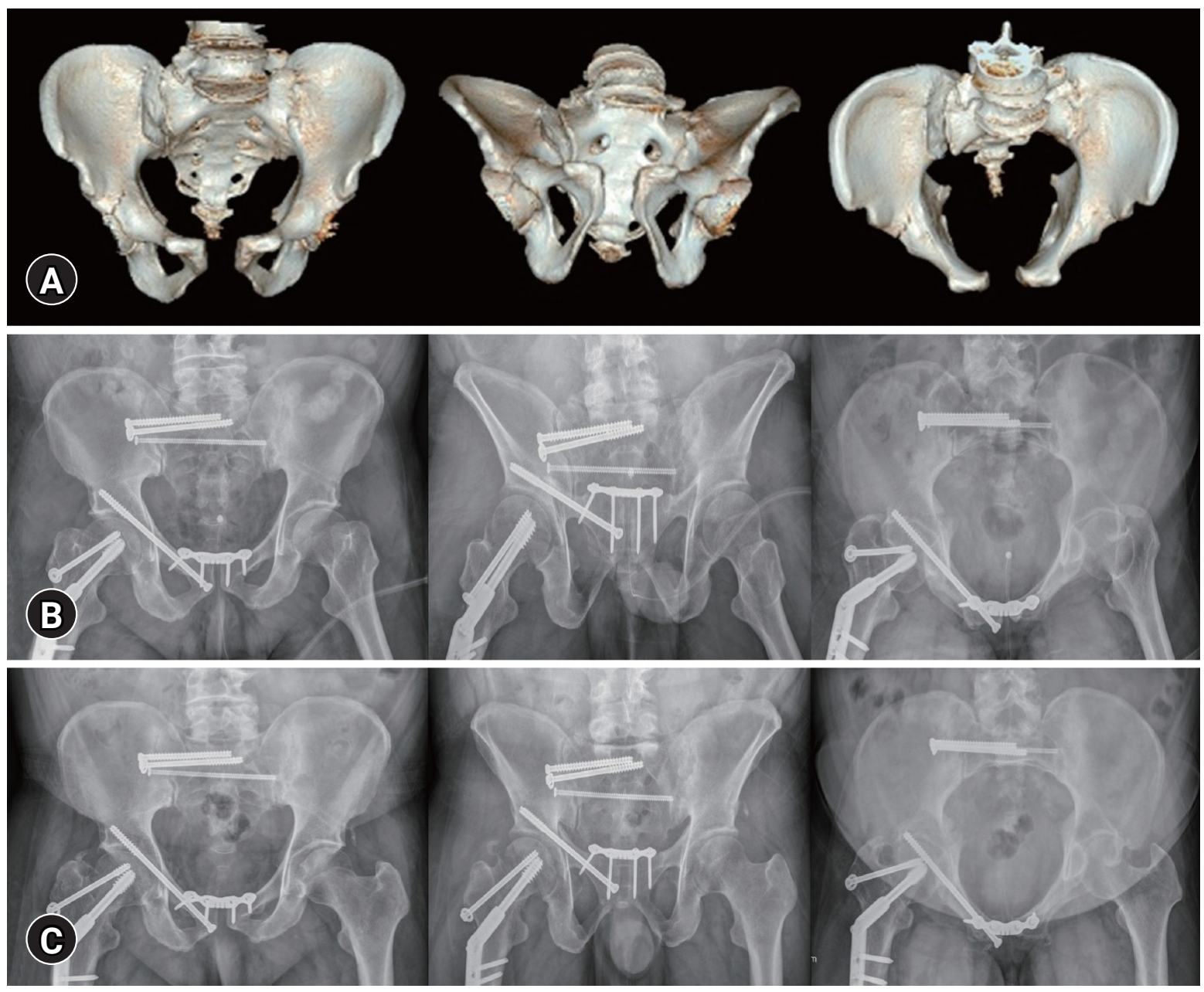

Fig. 4. A 46-year-old male patient suffered from an anterior-posterior compression type III pelvic ring injury after a crushing injury with an Injury Severity Score of 9. (A) Preoperative three-dimensionally reconstructed computed tomography images (anteroposterior [AP], outlet, and inlet). (B) Immediate postoperative plain radiographs (AP, outlet, and inlet) after percutaneous two ipsilateral iliosacral S1 screw fixation, transiliac-transsacral S2 screw fixation, retrograde pubic ramus screw, and anterior plate fixation. Percutaneous two ipsilateral iliosacral S1 screw fixation required 30 minutes, and no intraoperative complications were observed. (C) Follow-up plain radiographs (AP, outlet, and inlet) 97 days postoperatively. Radiographs showed bone union, and the outcomes were excellent according to the Matta and Tornetta grade. However, widening of the symphysis pubis $(<2.5 \mathrm{~mm})$ was noted. The patient provided written informed consent for publication of the research details and clinical images.

sults are comparable to those of other studies that used percutaneous IS screws or open reduction and plate fixation [12-14]. The results of the Matta and Tornetta grades were also comparable to or better than those of other studies. Matta and Tornetta et al. [8] reported an excellent grade in $67 \%$ of patients, good in $28 \%$, fair in $4 \%$, and poor in $1 \%$. In addition, Suzuki et al. [15] reported an excellent grade in $51 \%$ of patients, good in $23 \%$, fair in $16 \%$, and poor in $10 \%$. Furthermore, Khaled et al. [7] reported an excellent grade in $71.4 \%$ of patients, good in $20.8 \%$, fair in $7.8 \%$, and poor in none. There were no intraoperative complications; however, eight patients developed postoperative complications. In particular, S1 screw loosening (2.6\%), widening of the symphysis pubis (5.3\%), lumbosacral plexopathy (2.6\%), and S1 radiculopathy $(2.6 \%)$ were directly related to two unilateral IS S1 screws. Moreover, all neurological deficits recovered spontaneously; the 2.3- and 2.5-mm widenings of the symphysis pubis after surgery were relatively smaller than the mean values in previous studies [16-19]. The results for complications are also comparable to the findings of a study on a single IS screw; Osterhoff et al. [1] performed percutaneous single IS screw fixation on the S1 or S2 vertebrae in 38 patients and reported persistent hypoesthesia in L5/S1 dermatomes in two patients (5.3\%); screw malpositioning or loosening, which needed secondary surgery, in four (10.5\%); pulmonary embolism in one (2.6\%); and nonunion in 
one (2.6\%). Zwingmann et al. [20] evaluated the intraoperative and postoperative complications of the CT guidance and conventional technique groups for percutaneous IS screws in $784 \mathrm{pa}-$ tients and reported intraoperative and postoperative complications in $8.8 \%$ and $26.3 \%$ of patients in the CT guidance group and $5.9 \%$ and $29.3 \%$ of patients in the conventional technique group, respectively. Therefore, in this study, percutaneous two unilateral IS S1 screw fixation required a short procedure time and showed a small amount of blood loss, $100 \%$ bone union rate, comparatively good radiological outcomes, and few complications.

The limitations of this study are the retrospective study design and small number of cases, particularly for the outcome of $\mathrm{Hb}$ loss. In addition, this study was a case series and did not include a control group. Moreover, the outcomes of this study included many variables that were not controlled, including the initial fracture type or the fixation construct of the anterior pelvic ring. Thus, an additional study with a large number of cases and high power is needed.

In conclusions, percutaneous two unilateral IS S1 screw fixation is a useful option for pelvic ring injuries. In particular, the procedure requires less time and causes little blood loss, as well as leading to a $100 \%$ bone union rate and good radiological outcomes.

\section{NOTES}

\section{Ethical statement}

This study was a retrospective review of a prospectively collected cohort at a level 1 trauma center, Korea University Guro Hospital and approved by the Institutional Review Board of the Korea University Guro Hospital (No. 2021GR0439). Written informed consent was waived due to the retrospective nature of this study.

\section{Conflicts of interest}

The authors have no conflicts of interest to declare.

\section{Funding}

None.

\section{Author contributions}

Conceptualization: WSS, JWC, JKO; Data curation: HJK, NYK; Formal Analysis: NJC; Investigation: JMC; Methodology: JMC, NJC; Project administration: JKO, NYK; Resources: JKO; Software: WSS; Supervision: CWC, HJK; Validation: HJK; Visualization: WSS; Writing-original draft: WSS; Writing-review\&edit- ing: WSS, HJK, JWC, JKO.

All authors read and approved the final copy of the manuscript.

\section{REFERENCES}

1. Osterhoff G, Ossendorf C, Wanner GA, Simmen HP, Werner CM. Percutaneous iliosacral screw fixation in S1 and S2 for posterior pelvic ring injuries: technique and perioperative complications. Arch Orthop Trauma Surg 2011;131:809-13.

2. Giannoudis PV, Tzioupis CC, Pape HC, Roberts CS. Percutaneous fixation of the pelvic ring: an update. J Bone Joint Surg Br 2007;89:145-54.

3. Abou-Khalil S, Steinmetz S, Mustaki L, Leger B, Thein E, Borens $\mathrm{O}$. Results of open reduction internal fixation versus percutaneous iliosacral screw fixation for unstable pelvic ring injuries: retrospective study of 36 patients. Eur J Orthop Surg Traumatol 2020;30:877-84.

4. van Zwienen CM, van den Bosch EW, Snijders CJ, Kleinrensink GJ, van Vugt AB. Biomechanical comparison of sacroiliac screw techniques for unstable pelvic ring fractures. J Orthop Trauma 2004;18:589-95.

5. Suda AJ, Helm L, Obertacke U. Pelvic antropometric measurement in 3D CT for placement of two unilateral iliosacral S1 - 7.3 mm screws. Int Orthop 2021;45:3179-84.

6. van den Bosch EW, van Zwienen CM, van Vugt AB. Fluoroscopic positioning of sacroiliac screws in 88 patients. J Trauma 2002;53:44-8.

7. Khaled SA, Soliman O, Wahed MA. Functional outcome of unstable pelvic ring injuries after iliosacral screw fixation: single versus two screw fixation. Eur J Trauma Emerg Surg 2015; 41:387-92.

8. Matta JM, Tornetta P 3rd. Internal fixation of unstable pelvic ring injuries. Clin Orthop Relat Res 1996;(329):129-40.

9. Yinger K, Scalise J, Olson SA, Bay BK, Finkemeier CG. Biomechanical comparison of posterior pelvic ring fixation. J Orthop Trauma 2003;17:481-7.

10. Salari P, Moed BR, Bledsoe JG. Supplemental S1 fixation for type $\mathrm{C}$ pelvic ring injuries: biomechanical study of a long iliosacral versus a transsacral screw. J Orthop Traumatol 2015;16: 293-300.

11. Routt ML Jr, Simonian PT, Mills WJ. Iliosacral screw fixation: early complications of the percutaneous technique. J Orthop Trauma 1997;11:584-9.

12. Gras F, Marintschev I, Wilharm A, Klos K, Muckley T, Hofmann GO. 2D-fluoroscopic navigated percutaneous screw fixation of pelvic ring injuries: a case series. BMC Musculo- 
skelet Disord 2010;11:153.

13. Chen HW, Liu GD, Fei J, et al. Treatment of unstable posterior pelvic ring fracture with percutaneous reconstruction plate and percutaneous sacroiliac screws: a comparative study. J Orthop Sci 2012;17:580-7.

14. Khaleel VM, Pushpasekaran N, Prabhu N, Pandiyan A, Koshy GM. Posterior tension band plate osteosynthesis for unstable sacral fractures: a preliminary study. J Clin Orthop Trauma 2019;10(Suppl 1):S106-11.

15. Suzuki T, Shindo M, Soma K, et al. Long-term functional outcome after unstable pelvic ring fracture. J Trauma 2007;63: 884-8.

16. Eastman JG, Krieg JC, Routt ML Jr. Early failure of symphysis pubis plating. Injury 2016;47:1707-12.
17. Collinge CA, Archdeacon MT, LeBus G. Saddle-horn injury of the pelvis. The injury, its outcomes, and associated male sexual dysfunction. J Bone Joint Surg Am 2009;91:1630-6.

18. Morris SA, Loveridge J, Smart DK, Ward AJ, Chesser TJ. Is fixation failure after plate fixation of the symphysis pubis clinically important. Clin Orthop Relat Res 2012;470:2154-60.

19. Lybrand K, Bell A, Rodericks D, Templeman D, Tornetta P 3rd. APC injuries with symphyseal fixation: what affects outcome. J Orthop Trauma 2017;31:27-30.

20. Zwingmann J, Sudkamp NP, Konig B, et al. Intra- and postoperative complications of navigated and conventional techniques in percutaneous iliosacral screw fixation after pelvic fractures: results from the German Pelvic Trauma Registry. Injury 2013;44:1765-72. 